\title{
Maria Lúcia Namorado e a Literatura Portuguesa para a Infância: sobre um magistério assinalável
}

\author{
Sara Reis da Silva \\ IE-CIEC-Universidade do Minho \\ https://orcid.org/0000-0003-0041-728X
}

[Recibido, 26 setembro 2020; aceptado, 9 novembro 2020]

[Reis da Silva, S. (2020). Maria Lúcia Namorado e a Literatura Portuguesa para a Infância: sobre um magistério assinalável. Boletín Galego de Literatura, 57, "Estudos", 53-66] DOl http://dx.doi.org/10.15304/bgl.57.7134

RESUMO Na historiografia literária portuguesa, continua por completar aquela que se refere à literatura infanto-juvenil (LIJ), já iniciada por Lemos (1972), Pires (1982), Rocha (1984/2001) e Gomes (1997). O período que compreende o Estado Novo (19261974), conquanto já abordado, mesmo restritamente, reclama pesquisa académica, a desenvolver acerca da obra de diversos autores ou sobre temáticas como censura e LIJ. O caso de Maria Lúcia Namorado (1909-2000), figura marcante com uma acção cultural, social e pedagógica variada, merece atenção. Pretendemos analisar a sua escrita para os mais novos, designadamente os volumes, "merecedores de referência" (Gomes, 1997, p. 40), O Sonho do Infante (1960), A História do Pintainho Amarelo (1966), uma das primeiras obras para a infância sobre a reabilitação de cegos em Portugal, e A História de um Bago de Milho (1968), "dois livros de cunho moralista e pedagógico" (Rocha, 1984, p. 98), Era uma vez... (1970), uma colectânea de textos de origem popular, e Aventuras do Janoca e do Janeca (1971). A partir da análise das principais linhas ideotemáticas e dos mais relevantes mecanismos retórico-estilísticos patentes nestes títulos, conjunto que consubstancia um "magistério que cumpre assinalar" (Gomes, 1997, p. 40), concluiremos acerca da presença singular de Maria Lúcia Namorado na História da LIJ Portuguesa.

PalABRAS CHAVE: Literatura portuguesa para a infância; Maria Lúcia Namorado; Estado Novo.

ABSTRACT Portuguese literary historiography with regard to Children and Young Adults Literature (CYAL) continues to be completed, after it was first studied by Lemos (1972), Pires (1982), Rocha (1984/2001) and Gomes (1997). Estado Novo period (1926-1974) needs to be investigated by scholars, particularly as regards different authors works and topics such as censorship and CYAL. The case of Maria Lúcia Namorado (1909-2000), an important figure who has done cultural, social and pedagogical actions, deserves our attention. We will analyze her literary work for young people, specifically those volumes "merecedores de referência" (Gomes, 1997, p. 40), O Sonho do Infante (1960), A História do Pintainho Amarelo (1966), one of the first works for children about the rehabilitation for blind people in Portuga, and A História de um Bago de Milho (1968), "dois livros de cunho moralista e pedagógico" (Rocha, 1984, p. 98), Era uma vez... (1970), a collection of popular origin texts, and Aventuras do Janoca e do Janeca (1971).

KEYWORDS: Portuguese children's literature; Maria Lúcia Namorado; Estado Novo. 


\section{Introdução}

Em Para uma História da Literatura Portuguesa para a Infância e a fuventude, José António Gomes inclui Maria Lúcia Namorado (1909-2000), juntamente com Maria Cecília Correia (1919-1993), Maria Isabel de Mendonça Soares (1922-2017), Isabel da Nóbrega (1925-), Maria Isabel César Anjo (1927-2013) ou Madalena Gomes (1928-2010), no conjunto de nomes que "noutro contexto, mereceriam, por certo, melhor atenção" (Gomes, 1997, p. 67). Trata-se, com efeito, de um apontamento revelador do reconhecimento do mérito de uma autora que já anteriormente, na abordagem histórica empreendida por Natércia Rocha (1984), por exemplo, foi sendo também assinalado, a partir da alusão não apenas a algumas das suas obras para a infância, mas também à sua acção multímoda, ou melhor, ao seu projecto educativo -chamemos-lhe assim- de aproximação dos livros e da leitura dos leitores mais jovens.

A literatura para a infância ocupou, no percurso de Maria Lúcia Namorado, um lugar significativo, uma linha criativa de particular interesse que, na verdade, fez parte desse projecto mais lato ao qual vimos de aludir. Recorde-se, por exemplo, que, em 1968, aquando da criação da secção portuguesa do IBBY (International Board on Books for Young People), Maria Lúcia Namorado, juntamente com Leonoreta Leitão e Natividade Correia, integrou a comissão de leitura. Não sendo autora de extensa obra (em formato de livro) com destinatário explícito infantil, os volumes que editou durante o Estado Novo -O Sonho do Infante (1960), A História do Pintainho Amarelo (1966), A História de um Bago de Milho (1968), Era uma Vez... (1970) e Aventuras do Fanoca e do Faneca (1971), além de O Meu Livrinho de Provérbios (1971), O Meu Livrinho de Quadras (1974) e O Meu Livrinho de Adivinhas (1974), textos tradicionais recolhidos pela autora ${ }^{1}$ (títulos aos quais juntou, em 1984, o texto dramático O Segredo da Serra Azu [Livros Horizonte])- compõem

1 Pires (1983, p. 120) regista que "[...] entre os escritores para crianças creio que apenas Maria Lúcia Namorado explorou este campo na sua colecção "Os Livros da Grande Roda", a que pertence $O$ Meu Livrinho de Provérbios. A esta colecção de livros graduados pertence também O Meu Livrinho de Quadras e O Meu Livrinho de Adivinhas, todos eles amplamente ilustrados". A recomendação para estes estes três volumes era "Para as crianças lerem".

2 Glória Bastos destaca o "registo fabulístico [...] para evidenciar os defeitos e as virtudes dos seres humanos" (Bastos, 2006, p. 253), pormenorizando, ainda, "Mais convencional é o tratamento da problemática das relações entre o sujeito e a família no texto de Maria Lúcia Namorado [...] escrito em tom de fábula, com protagonistas animais "sentindo" como gente. 
um importante legado, uma produção na qual, não obstante a dificuldade de se produzir "qualidade debaixo duma pressão autoritária" (Araújo, 2008, p. 110) -note-se que, em 1950, são aprovadas Instruções sobre Literatura Infantil pela Direcção dos Serviços de Censura-, se constata um conjunto de linhas ideotemáticas e de mecanismos retórico-estilísticos que diferenciam a autora e que permitem singularizar um estilo pessoal.

\section{Análise do corpus textual}

Antes da edição de $A$ História do Pintainho Amarelo (1966), uma das primeiras obras para a infância sobre a reabilitação de cegos em Portugal, com ilustrações de Maria Keil (1914-2012), veio a lume, em 1960, o mesmo ano da publicação de A Noite de Natal, de Sophia de Mello Breyner Andresen (1919-2004), e Mosquito e o Senhor Pechincha, de Ilse Losa (1913-2006), a peça infantil $O$ Sonbo do Infante. Por restrições no acesso físico a esta obra ${ }^{3}$, vimo-nos forçados a deixar a sua análise mais aprofundada para outro contexto. Em todo o caso e como registámos em outro lugar (Silva, 2016), esta obra é "uma breve peça infantil que, pontuada por elementos de índole patriótica e, de certo modo, didactizante, é um panegírico a D. Henrique, a partir de uma “evocação simples” desta figura histórica” (Silva, 2016, p. 55). Exemplificando textualmente o carácter didactizante do texto, adicionamos o seguinte excerto da obra: "Foi certamente a sólida formação moral daquele carácter íntegro e o desejo indomável de alargar os limites da Pátria ao serviço de Deus, que não o deixaram sossobrar ante a enormidade de tamanha empresa."

A História do Pintainho Amarelo, livro adaptado para vários formatos pela Gaia Inclusiva - Serviço de Leitura Especial da Biblioteca Municipal de Gaia, serviço que tem como principal finalidade a produção e disponibilização de materiais de leitura em formatos acessíveis (áudio (analógico e digital), Brai-

Desta vez, temos o contraste do discurso da mãe, marcado pelo conformismo, com o do filho, João Ratão, que anseia conhecer mundo, num processo que descreve como necessário ao seu próprio amadurecimento [...]. Este João Ratão defende assim uma posição de sujeito em que o valor da experiência se sobrepõe a um saber baseado em ideias feitas [...]. Mesmo se esse porquê vai desembocar no apontamento "politicamente correcto" de um gato, temido por todos os animais, e que afinal é vegetariano. De qualquer forma, sai reforçada a ideia de que é do conhecimento mútuo que nasce a compreensão e a harmonia, vertente tematizada ainda noutros textos." (Bastos, 2006, p. 277-278).

3 Este breve estudo foi finalizado em pleno período de confinamento, devido à pandemia Covid19. 
lle e documento informático de texto), representa um gesto inserido num conjunto de outros empreendidos pela autora no sentido de avançar com estratégias para a resolução do problema das pessoas cegas em Portugal ${ }^{4}$, é uma obra publicada na colecção "Bandeiras de Todo o Mundo" (dirigida por Matilde Rosa Araújo) que ostenta o seguinte paratexto (muito possivelmente, da autoria da directora da colecção) a anteceder a narrativa: "O mundo / é formado por vários países / cada um com a sua bandeira. / E em todos eles / há crianças como vocês / que amam, brincam e participam / na grande aventura da vida." (Namorado, 1966). Este volume oferece uma narrativa, sequenciada em quinze partes todas tituladas, a saber: "Uma família galinácia", "Nasceram duas ninhadas de passarinhos", "Há um pintainho diferente", "O que terá o amarelinho?”, "CÁ-CÁ-RÁ-CÁ, que desgraça, cada qual teve uma ideia", "Entra na história o verde gaio", "Quem ajuda o amarelinho a ser feliz"?, "O Verde Gaio vai visitar o amarelinho", "Apresenta-se a Lagartixa Rabicha”, "Querer é poder; parar é morrer”, "As lições da Lagartixa Rabicha", "Preparativos para o Inverno", "Viver é pensar e trabalhar" e "Houve festa no pinhal".

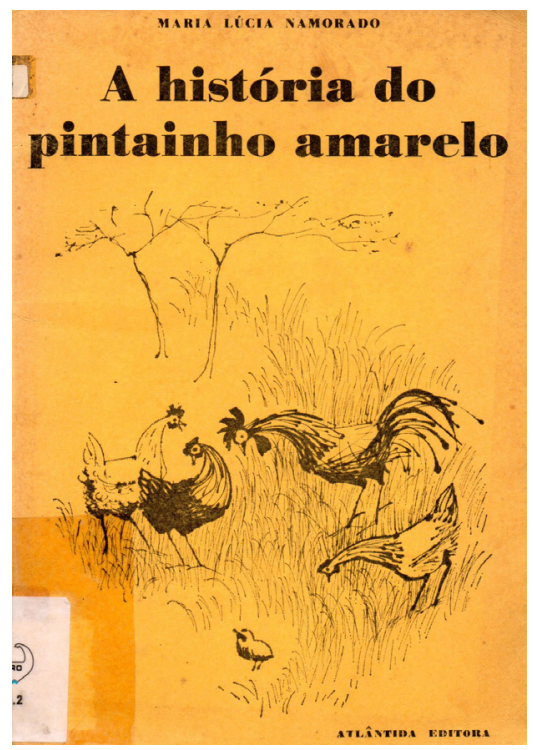

Figura 1. Capa de A História do Pintainho Amarelo.

\footnotetext{
4 "Maria Lúcia Namorado envidaria, ao longo da sua vida, várias acções com o objectivo de apontar caminhos para a resolução do problema das pessoas cegas em Portugal. Nesta linha, inserem-se as duas conferências realizadas pela torrejana ilustre no Clube Fenianos Portuenses em 15 de Outubro de 1956 (Mensagem de Helen Keller) e a 10 de Maio de 1963 (A fundação Sain e a Reabilitação das Pessoas Cegas em Portugal)." (Antunes, 2018).
} 
Tendo como principal eixo ideotemático o direito à diferença, perpassam também a obra outras linhas como a entreajuda, a solidariedade, a união, a dedicação, a perseverança, o sentido de família e de comunidade ou, mesmo, a valorização da própria condição feminina (que ressuma das personagens animais personificadas). Sobre este último tópico, retomem-se as seguintes palavras de Ana Pessoa:

Mulher determinada e minuciosa, atenciosa e tenaz, exigente na formação do carácter das raparigas, foi autora de contos incluídos em manuais escolares para o ensino primário, sócia fundadora do Instituto de Apoio à Criança e colaboradora da Fundação Sain (directora do centro de reabilitação para cegos recentes). A promoção da educação de raparigas em igualdade de circunstâncias com os rapazes e a visão de que as mulheres podem ultrapassar a ignorância através do estudo são duas das facetas que mais a caracterizam como educadora e pedagoga. (Pessoa, 2003, p. 972)

Ao jeito da fabulística tradicional, este conto é protagonizado por animais, em particular galinácios (a Galinha Vermelha, a Galinha, Pedrês, a Galinha Branquinha, o Galo Pimpão e todos seus filhos), mas também aves e outros (Lagartixa Rabicha, Verde Gaio, Perdiz Pintalegrete, Rola Cinzenta, Formiga, Mocho, Lebre, uma Borboleta e até o Vento e o Ribeirinho) que assumem papéis, vivenciam situações e lidam com sentimentos, valores, virtudes e defeitos profundamente humanos. O nascimento de um pintainho cego -uma temática que, especialmente à época da edição da obra, se revela fracturan$\mathrm{te}^{5}$ - deixa todos sem saber o que fazer, como ajudá-lo a viver. O Pintainho Amarelo (Amarelinho) descobre, com o apoio dos seus companheiros, como é possível ser feliz, sentir-se bem, desempenhar um papel social, apesar da diferença física que o caracteriza. Se o fundo ético-moral é ostensivo -veja-se a assiduidade de expressões sentenciosas como "Querer é poder; Parar é morrer" ou "Viver é pensar e trabalhar"-, a verdade é que este facto não obscurece a qualidade do registo literário. Com efeito, esta narrativa de Maria Lúcia Namorado, obra que permanece, a vários títulos -quer seja pela configuração ideotemática, quer seja pela forte presença animal, quer seja, ainda, pela expressividade do discurso literário-, actual, evidencia um discurso vivo, muito envolvente, cuja expressividade assenta essencialmente no recurso bem doseado ao discurso directo, em diálogos muito animados e verosímeis, na

5 "Neste caso a cegueira. A seriedade e delicadeza do assunto originaram a recusa do livro por parte da Comissão de Leitura da Gulbenkian. Considerando-o inapropriado para a frágil maturidade das crianças." (Antunes, 2018). 
adjectivação expressiva -que, em certos casos, não deixa de imprimir um certo sentido cómico (veja-se, por exemplo, os nomes próprios (em certos casos, quase apelidos) de animais como Pimpão, Pinto Calçudo, Vermelhusco Patusco, Pintadinha, Lagartixa Rabicha, entre outros)-, o sensorialismo, na rima entre/de certas expressões, entre outros. Releia-se apenas um segmento exemplificativo:

Nisto, o Pinto Calçudo levantou uma asa e disse:"

-Se me dá licença, tenho uma coisa a dizer!

-Fala! -autorizou o Pimpão.

-Na parte de cima do pinhal há um casebre em ruínas que para nós é um verdadeiro palácio. Ainda tem restos de telhado e paredes, tudo coberto com silvas e madressilvas muito fortes, de modo que a chuva e o vento não podem lá entrar. -Conheço esse casebre -disse a Pedrês- e sou da mesma opinião.

-Nesse caso, vamos todos conhecer a nossa nova residência de Inverno. Sigam à frente a Pedrês e o Pinto Calçudo -ordenou o Galo Pimpão.

Puseram-se todos em marcha. E, pela primeira vez, no meio deles, seguia o Amarelinho, todo contente. Não precisava de ajuda, não incomodava ninguém, porque ia no meio dos outros, com a sua bengalinha. $\mathrm{O}$ som das conversas e dos passos orientavam-no; e a bengalinha ia-o avisando: Por aqui... Por aqui... Por aqui!... (Namorado, 1966, p. 45)

As ilustrações de Maria Keil, compostas a traço fino, primam pela sobriedade e pela discrição, revisitando alguns dos momentos actanciais mais relevantes, recriando algumas das suas personagens e dotando a publicação de breves espaços de contemplação estética que favorecem a aproximação ao texto.

Igualmente inscrita no modo narrativo, A História de um Bago de Milho é dada à estampa em 1968 , ano da edição também de outras obras que ocupam um lugar irrecusável na História da Literatura Portuguesa para a Infância, a saber: Este Livro tão Bonito e Os Quatro Corações do Coração, de Ricardo Alberty (1919-1992); A Floresta, de Sophia de Mello Breyner Andresen; e "Maria Flor" (1968-1970), de Alves Redol (1911-1969).

6 Na capa da $2^{a}$ edição (1972), pode ler-se "Edição especial patrocinada pela Direcção-Geral da Educação Permanente". O mesmo se verifica, no mesmo ano, relativamente à obra $A$ História da Papoila, de Luísa Ducla Soares. Neste estudo, todas as citações são retiradas da segunda edição desta obra. 


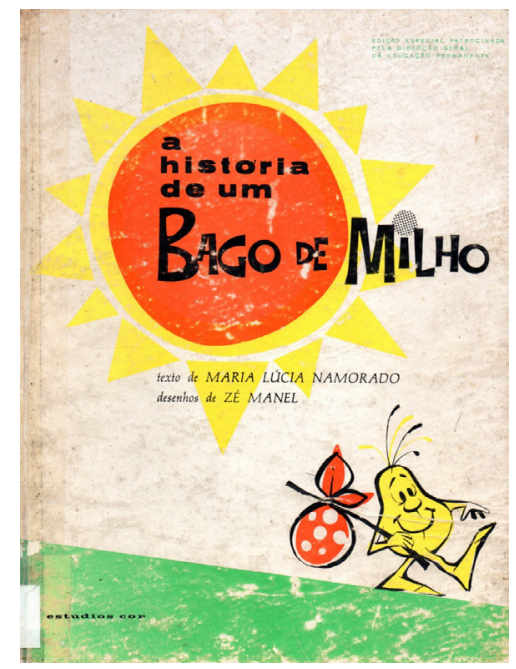

Figura 2. Capa de A História de um Bago de Milho.

Como propõem cataforicamente o título e a ilustração da capa deste volume, conta-se, em dezoito partes ${ }^{7}$, o percurso vivencial atribulado de um grão de milho que, ajudado pelo Vento, encontra sentido para a sua vida e realiza-se pessoalmente. Uma vez mais, num especial tom dialógico, o relato prende a atenção pela presença entusiasmada das personagens personificadas (como o protagonista, o Vento ou a própria Primavera), pela aventura que são, afinal, as viagens feitas pelo pequeno herói (uma pelo ar e outra pela terra), pela expressividade do discurso, pontuado de enumerações, de uma especial adjectivação, de sensações visuais e olfactivas, de segmentos exclamativos, de onomatopeias, entre outros. Acresce, ainda, a assiduidade de formas verbais actanciais, por vezes, reiteradas (por exemplo, "Foram andando, andando; subiram a colina" [Namorado, 1972, p. 37]), a imprimirem um cativante dinamismo ao relato.

Motivos temáticos como a esperança, a entreajuda, a capacidade de sonhar, a coragem, a persistência, o optimismo, mas também o valor do trabalho, por exemplo, surgem, de novo, ficcionalizados neste conto de Maria Lú-

7 Cada uma das partes, sequenciadas por encadeamento, é intitulada: "O que disse o vento", "Uma grande viagem", "Acabou a viagem", "Um moinho abandonado", "O que disse o vento", "A ideia do bago de milho", "O vento aprovou a ideia", "Uma viagem diferente", "A mensagem da Primavera", "Uma missão a cumprir", "A voz da Primavera", "O velho moinho", "O minho voltou a cantar", "Passou quase um ano", "O encontro de velhos amigos", "Um rica merenda", "Cada cabeça cada sentença" e "Cada um tem de usar a sua força". 
cia Namorado, uma narrativa da qual, uma vez mais, não se encontra ausente um certo tom sentencioso.

Trata-se, ainda, de um volume original do ponto de vista da composição visual ou, em termos mais latos, no que diz respeito ao seu grafismo global, um registo da autoria de Zé Manel (1944-2019) ${ }^{8}$. Nesta publicação, destaca-se, além da estratégia cromática do contraste das linhas/traços a negro com manchas/preenchimentos de cores como o verde ou o laranja, sempre num estilo muito contido ou económico, a opção frequente pela ilustração em página dupla, espaços visuais nos quais surgem recriadas, em leves tons caricaturais, as personagens que intervêm na acção, situadas em cenários escassamente decorados. Muito inovador é o facto das próprias guardas finais do livro se apresentarem ilustradas, uma composição pictórica que parece introduzir novas personagens.

Estes "dois livros de cunho moralista e pedagógico" (Rocha, 1984, p. 98), que vimos, agora, de analisar, podem ser, portanto, entendidos como um díptico não apenas pelo denominador comum que marca os seus títulos (o vocábulo "história"), mas também, e muito especialmente, por aspectos que se prendem com algumas das linhas isotópicas que os perpassam e por traços comuns de linguagem e estilo que permitem, com efeito, singularizar a escrita de Maria Lúcia Namorado.

Em 1970, na colecção “Os Livros da Grande Roda”, projecto com plano e direcção de Maria Lúcia Namorado, é publicado Era uma vez... (1970), uma colectânea destinada a "crianças de 2 a 9 anos" (como se pode ler na folha de rosto do volume) que contém "Rimas, jogos, canções, lenga-lengas e contos para as mães ensinarem ou lerem aos filhos”.

Neste volume, composto por formas poético-líricas ( $1^{\text {a }}$ parte) e contos da tradição oral ( $2^{\mathrm{a}}$ parte), incluiu-se uma relevante introdução, peritexto intitulado "A criança e o livro", subdividido em catorze secções breves, a saber: "O conto, elo da ligação afectiva", "Em que idade começaremos a contar contos às crianças?", "O livro, amigo que se ama e respeita", "Contar, o quê,

8 Sobre este ilustrador, vide: SILVA, Sara Reis da (2019). "As ilustrações de Zé Manel para as narrativas de Luísa Ducla Soares: inovação e experimentalismo" in Confia 2019 7th International Conference on Illustration \& Animation (14-16 de Junho) - Atas. Barcelos: IPCA, pp. 495-503. 
às crianças mais pequenas? E às mais velhinhas?", "Ler ou contar?", "Ouvinte único, ou grupo de ouvintes", "E depois do conto, e a ele ligado, o desenho, a mímica, etc.", "Que é um bom conto infantil? Que pretendemos dar à criança através do conto?", "Contos de fadas", "Contos tradicionais", "As maravilhas da natureza e da ciência", "Histórias aos quadradinhos", "Género e qualidade" e "Um problema; escolher".

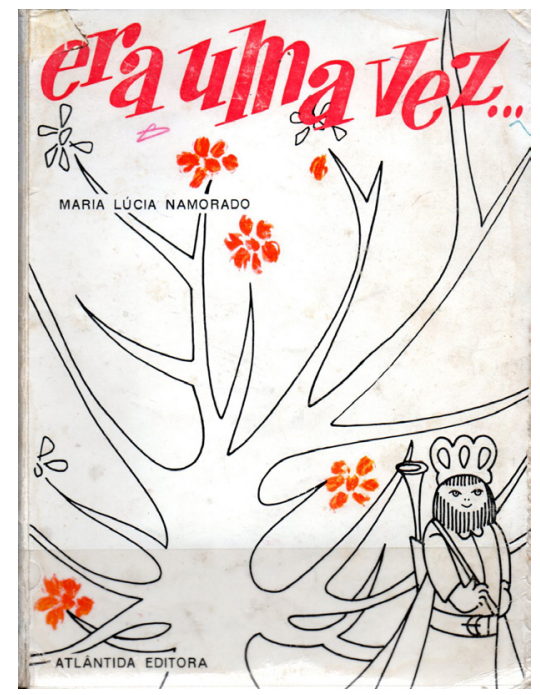

Figura 3. Capa de Era uma Vez....

Neste peritexto, "Maria Lúcia Namorado expõe ideias de muito interesse sobre os problemas de leitura e de literatura para crianças" (Rocha, 1984, p. 98), perspectiva posteriormente expandida, aquando da menção às mudanças que se começam a sentir no campo da edição e do livro infantil com a proximidade da Revolução de Abril:

Formam-se colecções novas, algumas expressamente vocacionadas para a apresentação de autores portugueses. Um projecto, estruturado por Maria Lúcia Namorado, para levar o livro às crianças, antes de atingirem a idade escolar, é exposto no prefácio do livro Era uma vez... e está na origem do plano de uma colecção assente no estudo dos interesses e gostos das crianças mais pequenas. A proposta, na linha já adoptada por editores ingleses e franceses (Ladybird e Père Castor), não teve a continuidade merecida, mas bastou para evidenciar carências e soluções possíveis. (Rocha, 1984, p. 105)

Maria Laura Bettencourt Pires, muito sucintamente, deixa também um apontamento similar: "Começaram também a surgir bibliotecas escalonadas 
por idades, tais como, por exemplo, Os Livros da Grande Roda, de Maria Lúcia Namorado, o que de certo modo, constitui uma ajuda importante para quem os compra." (Pires, 1983, p. 93).

Muito embora este volume não conte com escrita ficcional assinada por Maria Lúcia, o facto é que a sua edição é reveladora da relevância que a autora atribui à literatura tradicional e ao contacto precoce, afectivamente mediado, com esta por parte da criança.

Por fim, centremos a atenção em Aventuras do Fanoca e do faneca (1971), volume igualmente inserido na colecção "Os livros da grande roda", em concreto na Série "Cata-vento", constituindo o seu número inaugural e destinando-se, conforme inscrição paratextual patente na contracapa, a leitores dos 8 aos 12 anos.

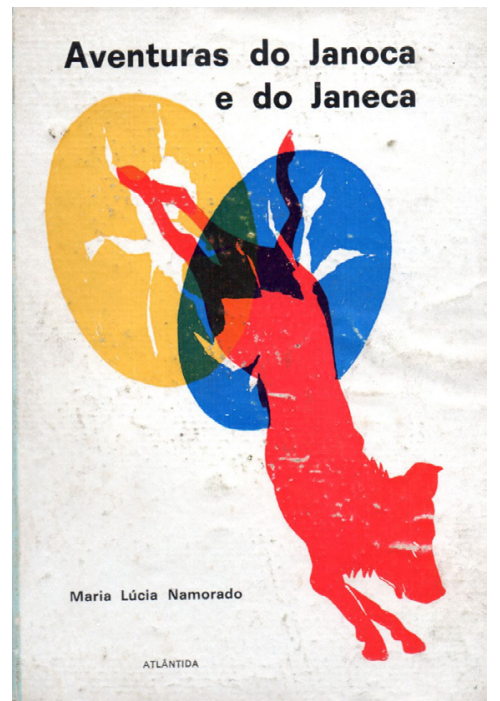

Figura 4. Capa de Aventuras do Fanoca e do Faneca.

Nesta obra, reúnem-se duas narrativas: uma que empresta o título à publicação e outra intitulada "A história de Giribi”. Na primeira, coabitam dois amigos que têm duas vacas, uma preta e outra branca, andam na escola (na $4^{\mathrm{a}}$ classse), colhem amoras e vivem um quotidiano típico de uma infância passada na aldeia, no seio da natureza. As travessuras dos dois animais constituem uma das peripécias fundamentais do relato, também marcado pela aventura da descoberta e da entrada numa espécie de caverna, repleta de pedras apa- 
rentemente preciosas ("uma mina de prata e diamantes" [Namorado, 1971, p. 41]), um segredo bem guardado, apenas partilhado com a sua professora (que muito prezam). É esta que, aliás, resolve o mistério e esclarece que as pedras são, afinal, uma pedra muito comum: mica. A narrativa evidencia, assim, alguns ingredientes que prendem a atenção do potencial destinatário, designadamente: o protagonismo infantil, a aventura e o (relativo) mistério, o tópico da amizade, o humor ou o cómico de situação, entre outros.

Também em "A História de Giribi", o papel principal é concedido a figuras infantis (Rita, João e Tonecas) em idade escolar. São três amigos inseparáveis que, um dia, encontram um cão e decidem tratar dele. E, assim, este também passa a ser um companheiro sempre presente, apesar da crispação do gato da Rita, o Tareco, da dúvida quanto ao canário do João e do peixe vermelho e doirado do Tonecas. Em termos genéricos, o conto desenvolve-se em torno do quotidiano destas crianças, um dia-a-dia feito de brincadeiras e de cumplicidades, que substantivam o que de mais simples caracteriza a infância.

Se, do ponto de vista ideotemático, esta é uma obra da qual ressumam, uma vez mais, tópicos como a amizade, a bondade, a união, o respeito mútuo, entre outros, o estilo do relato afigura-se distinto do díptico inicial que analisámos. Na verdade, nestas narrativas, observa-se, por exemplo, uma maior contenção no recurso a expressões de carácter sentencioso, opta-se por diálogos mais breves, mas igualmente vivos, e por segmentos descritivos mais sóbrios (chamemos-lhe assim). Há, porém, um aspecto do âmbito narratológico que merece referência, na medida em que se reveste de uma certa "modernidade", coincidindo com uma das tendências contemporâneas da escrita para a infãncia e a juventude. Trata-se do apontamento metatextual/metaliterário materializado no acto de escrita ficcional empreendido pelas próprias personagens da narrativa, quando decidem escrever a história do Giribi (Namorado, 1971, p. 111), gesto que constitui também o desfecho do relato.

\section{Considerações finais}

Não obstante o contexto histórico-político em que viveu, Maria Lúcia Namorado exerceu uma "assinalável acção" no domínio alargado da educação -não apenas de adultos e familiar, mas também de crianças-, uma ac- 
tividade reveladora da constante preocupação social da autora, que sempre procurou contribuir para a formação da mulher, em especial quando mãe, e para o bem-estar da criança. A atenção que dedicou à literatura para a infância consiste, pois, numa parte desse empenho e, concretamente no que tange a esta sua acção, importa referir que, nesta, é possível observar uma especial concomitância das duas vertentes que pautaram a criação literária no período do Estado Novo, a saber e como em outro lugar assinalámos (Silva, 2008): por um lado, a edição de títulos que, de maneira mais ou menos ostensiva, se enquadram nos modelos estéticos e socioculturais do regime e, por outro lado, a publicação de textos que se distinguem pela imaginação e pela vivacidade.

Assim, interseccionando os três núcleos semânticos ou motivos que desencadearam este breve estudo, ou seja, mulher, ditadura e arte/literatura para a infância, é possível concluir que a autora em análise, na mesma linha de outras figuras literárias femininas suas contemporâneas ${ }^{9}$, com quem, em muitos casos, mantinha um relacionamento próximo (Maria Lamas -laços familiares uniam esta autora e Maria Lamas (1893-1983), bem como Alice Vieira (1943-) a estas duas-, Maria Isabel César Anjo, Matilde Rosa Araújo, Maria Cecília Correia, por exemplo), ainda que com uma vida familiar absorvente, repartiu a sua escrita notoriamente prolífica por jornais e revistas (por exemplo, Modas \& Bordados), não apenas colaborando, mas também dirigindo e editando (como sucedeu com Os Nossos Filhos, projecto crucial no seu percurso, que inicia em 1942), bem como por livros de índole educativa e de ficção. Cultivou, pois, diversas tipologias textuais, divulgadas em diferentes suportes (que incluíram, por exemplo, a rádio e a televisão), fazendo da escrita uma constante no seu percurso vivencial e social.

Escritora e editora (no sentido da concepção e direcção de planos/projectos de edição), uma prática artística permanente e resiliente, mas também educadora e mediadora de leitura, acção assente num quadro teórico que, em muitos aspectos, se pauta, ainda, pela actualidade, Maria Lúcia Namorado, se

9 "Como era frequente na época, sobretudo para as senhoras, vai usar pseudónimos: Milú, com o qual assina artigos de conselhos às raparigas e sobre problemas domésticos; Tricana, desde Julho de 1935, sobre acontecimentos de relevo ocorridos na zona centro; e Dona Experiência, desde Julho de 1939, sobre culinária" (Pessoa, 2003, p. 971). Mais tarde, já nos anos 60, adopta pseudónimos como Telma (Diário de Lisboa - Magazine, na secção "Eduquemos o nosso filho"), Tia Luísa ou Tia Maria Luísa (Diário de Lisboa - Magazine, na secção "Para o mais pequenos") e Tião (no suplemento Diário de Lisboa Juvenil). 
indubitavelmente reconhecida pela sua actividade social, educativa e cultural $^{10}$, possui também, por tudo aquilo que aqui sucintamente expusemos, um justo lugar e uma relevante presença na História da Literatura Portuguesa para a Infância e a Juventude. E a verdade é que esta História -como preconiza José Mattoso, quando se refere à História em geral (Mattoso, 2019, p. 305)-, necessita de ser reescrita, gesto que reclama a compilação e análise crítica de dados sobre mulheres que escreveram/escrevem para a infância (e sendo assim aduzido um "novo fator de compreensão da totalidade" [Mattoso, 2019, p. 306], recorrendo, em grande medida, à interdisciplinaridade [Mattoso, 2019, p. 316]), muitas delas permanecendo no ainda amplo universo das "femmes oubliées dans les arts et les lettres au Portugal" (Besse e Silva, 2016).

\section{Bibliografia}

\section{Bibliografia activa}

Namorado, M. L. (1966). A História do Pintainho Amarelo. Atlântida Editora [ilustrações de Maria Keil].

Namorado, M. L. (1972). A História de um Bago de Milho. Estúdios Cor [ilustrações de Zé Manel].

Namorado, M. L. (1970). Era uma Vez.... Atlântida Editora [ilustrações de Maria Almira Medina].

Namorado, M. L. (1971). Aventuras do Fanoca e do Faneca. Atlântida Editora [ilustrações de Alice Jorge].

\section{Bibliografia passiva}

Antunes, V. (2018). Um conto infantil sobre a diferença. https://oalmonda.

\footnotetext{
10 Note-se que, após o 25 de Abril de 1974, Maria Lúcia Vassalo Namorado prossegue de forma mais livre e dinâmica as suas acções. Chega inclusivamente a assumir a docência da disciplina Literatura Infantil na Escola João de Deus e na Escola do Magistério Primário de Lisboa. Frequenta, entre outros, o curso de Introdução à Musicoterapia, na Fundação Calouste Gulbenkian, e Preparação Política do Movimento Democrático das Mulheres. Participa na Campanha de Alfabetização de Adultos e no $1^{\circ}$ e $2^{\circ}$ Congresso das Escritoras Portuguesas. Fez parte da Comissão Unitária de Mulheres do Alto do Pina foi sócia do CEFEPE - Centro de Formação e Educação Permanente - e uma das fundadora do Instituto de Apoio à Criança.
} 
net/?p=19873

Araújo, M. A. T. (2008). A Emancipação da Literatura Infantil. Campo das Letras.

Bastos, G. (2006). O Teatro para Crianças em Portugal. História e Crítica. Caminho.

Besse, M. G. e Silva, M. A.(coord.) (2016). Femmes Oubliées dans les arts et les lettres au Portugal (XIX.e-XX.e siècles). Indigo \& Côté-femmes éditions.

Castilho, C. (26 de avril de 2012). Pedagogos Portugueses - Maria Lúcia Namorado. A Viagem dos Argonautas. https://aviagemdosargonautas.net/2012/04/26/ pedagogos-portugueses-maria-lucia-namorado-por-clara-castilho/

Gomes, J. A. (1997). Para uma História da Literatura Portuguesa para a Infância e a Fuventude. Ministério da Cultura/Instituto Português do Livro e das Bibliotecas.

Lemos, E. (1972). A Literatura Infantil em Portugal. Ministério da Educação Nacional / Direcção-geral da Educação Permanente.

Mattoso, J. (2019). A Escrita da História. Temas e Debates / Círculo de Leitores.

Pessoa, A. M. (2003). Namorado, Maria Lúcia. En A. Nóvoa (Dir.), Dicionário de Educadores Portugueses (pp. 971-972). Edições Asa.

Pessoa, A. M. (2006). A Educação das Mães e das Crianças no Estado Novo: a proposta de Maria Lúcia Vassalo Namorado. Universidade de Lisboa. https://repositorio. ul.pt/handle/10451/2016

Pessoa, A. M. (2016). Revista Os Nossos Filhos: resistência e oposição ao Estado Novo - Um olhar sobre as ligações sociais e profissionais da sua autora. Faces de Eva. Estudos sobre a Mulher, 36. http://www.scielo.mec.pt/scielo.php?script=sci_artt ext\&pid=S0874-68852016000200008

66 Pires, M. L. B. (1983). História da Literatura Infantil Portuguesa. Vega.

Rocha, N. (1984/2001). Breve História da Literatura para Crianças em Portugal. Instituto de Cultura e Língua Portuguesa [Nova edição actualizada até ao ano de 2001, Editorial Caminho).

Silva, S. R da (2008). O País das Pessoas de Pernas para o Ar. En A. S. Paço (Ed.), Os Anos de Salazar - 1970 Marcha Fúnebre (pp. 154-161). Planeta deAgostini.

Silva, S. R. da (2016). Capitulos da História da Literatura Portuguesa para a Infância. Tropelias \& Companhia. 